\title{
Migrant and minority health in Europe: the way forward
}

\section{Report on the Salzburg Workshop on Migrant and Minority Health, 3-9 April 2016}

Tina Bregant ${ }^{{ }^{*}}$, Mariam Torosyan $^{2,3}$, Amanda Shriwise $^{4,5}$, Lukasz Balwicki ${ }^{6}$ and Ted Tulchinsky ${ }^{7,8}$

* Correspondence:

tina.bregant.drmed@gmail.com

'University Rehabilitation Institute, Republic of Slovenia, Ljubljana,

Slovenia

Full list of author information is available at the end of the article

\section{() Biomed Central}

\begin{abstract}
Migrant and minority health has always been an issue of special concern in public health. While migration is not a new phenomenon, the number of refugees and migrants across the globe grew rapidly in 2015, with large numbers from the Middle East and Africa. Furthermore, the recent migrant crisis in Europe-sparked by civil wars in Syria and Libya and continuing conflict in Iraq and Afghanistan-has escalated to the level of a humanitarian emergency requiring immediate action. We conducted an international workshop on migrant and minority health in Salzburg from 3 to 9 April 2016 to examine migrant and minority health issues in greater depth, sponsored by the American Austrian Foundation and in cooperation with the Association of Schools of Public Health in the European Region (ASPHER) and Public Health Reviews (PHR). To continue this discussion within the academic literature, $P H R^{\prime}$ s special issue on migrant and minority health includes articles from conference participants and other experts in medicine and public health from the European region and beyond.

Informed by the contribution of senior representatives of the European Union, the International Organization for Migration (IOM), Médecins Sans Frontières (MSF), and public health practitioners and investigators from over 30 countries, this editorial summarizes recommendations of the conference participants for improving migrant and minority health in Europe. They include (i) developing a conceptual framework for health care intervention for migrants, (ii) oversight and coordination of migrant and minority health activities, (iii) reaching a consensus on implementation practices, and (iv) mobilizing sufficient resources for addressing the health needs of migrants.
\end{abstract}

Keywords: Migrant health, Minority health, Europe, Public health

\section{Introduction}

The American Austrian Foundation and PHR-ASPHER conducted an international workshop on migrant and minority health in Salzburg from 3 to 9 April 2016. ${ }^{1}$ Public Health Reviews (PHR) is now publishing a special issue on migrant and minority health, and the conference participants included both authors of articles for this special issue and representatives of the Association of Schools of Public Health in the European Region (ASPHER) member schools across the European region.

(c) The Author(s). 2016 Open Access This article is distributed under the terms of the Creative Commons Attribution 4.0 International License (http://creativecommons.org/licenses/by/4.0/), which permits unrestricted use, distribution, and reproduction in any medium, provided you give appropriate credit to the original author(s) and the source, provide a link to the Creative Commons license, and indicate if changes were made. The Creative Commons Public Domain Dedication waiver (http://creativecommons.org/ publicdomain/zero/1.0/) applies to the data made available in this article, unless otherwise stated. 
Migrant and minority health has always been an issue of special concern in public health. The recent migrant crisis in Europe-sparked by civil wars in Syria and Libya and continuing conflict in Iraq and Afghanistan-has escalated to the level of a humanitarian emergency requiring immediate action [1,2]. While migration is not a new phenomenon, the number of refugees and migrants has grown rapidly in the past year, with large numbers originating from the Middle East and Africa. As of January 2015, the Office of the United Nations High Commissioner for Refugees (UNHCR) counts a total of 13,685,607 refugees worldwide and lists the total population of concern at 54,945,467 [3]. In Europe, UNHCR and the International Organization for Migration (IOM) estimate that over one million men, women, and children arrived in 2015 [4]; nearly 190,000 additional migrants have arrived as of May 2016, with many more continuing to make the arduous journey [5].

To examine migrant and minority health issues in greater depth, the Salzburg Workshop included presentations from senior representatives of the European Union, IOM, Médecins Sans Frontières (MSF), as well as public health practitioners and investigators from over 30 countries in Europe and beyond. Presentations were given on international organizations and also on national experiences with migrant and minority health issues. Workshop participants contributed to one of three working groups examining (i) the political aspects of the crisis, (ii) the public health effects, and (iii) their social implications.

\section{Principles}

From the outset, the Workshop participants recognized the following internationally sanctioned UN declarations and conventions as the foundation for understanding the current migration crisis: the 1948 Universal Declaration of Human Rights [6], the 1948 Convention on Prevention and Punishment for the Crime of Genocide [7], and the 1951 Convention Relating to the Status of Refugees-including the 1967 Protocol Relating to the Status of Refugees and Resolution 2198 (XXI) [8]. These documents establish the international norms of human rights, protection from genocide, and the rights of refugees. Despite these standards-many of which emerged in response to the bitter and tragic experience of World War II and the Holocaust, including the refugee crisis in its aftermath-genocide and forced migration continue. The current migration crisis in Europe has led to a renewed global commitment and a re-doubling of efforts to substantiate the rights of individuals seeking refuge from conflicts in the Middle East, Africa, the Balkans, and other parts of the world.

\section{Key issues}

Four key issues were identified to address migrant and minority health: (1) development of a conceptual framework for health care intervention, (2) oversight and coordination of migrant and minority health activities, (3) consensus on implementation practices, and (4) mobilization of sufficient resources. Figure 1 illustrates how attention to these key issues contributes to the coordination of migrant health policy.

A conceptual framework for addressing migrant health care interventions must consider and harmonize both health care and public health policies and practices. International organizations have a fundamental role to play in the oversight and coordination of migrant and minority health. Effective leadership from international organizations is critical, particularly for monitoring health and for coordinating health 


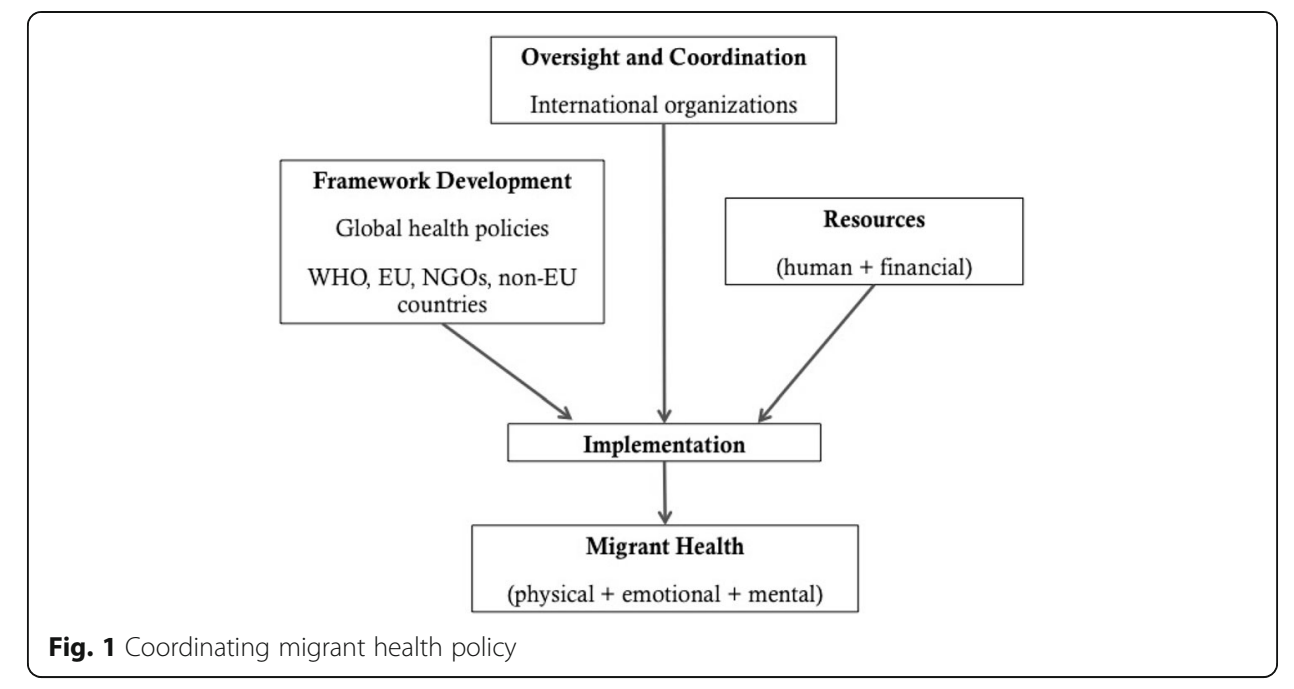

responses across borders. Achieving a consensus on implementation practices, such as a standard set of international health guidelines, could better facilitate communication between health professionals and ensure that theoretical principles are translated into clinical practice in a way that is both consistent and evidence-based. Finally, sufficient resources must be dedicated to providing public health protection and medical care to those in need. This includes educating policy makers, supervisory and health service staff, and community health workers on the unique health needs of migrants and minorities, which can be informed and facilitated by health care professionals with international experience.

Migrant and minority health includes not only physical health but also mental and emotional health. While the physical and material needs of refugees-shelter, safety, warmth, nutrition, sanitation, and health care-often take priority, the mental and emotional health needs of migrants are just as integral to their well-being. This includes encouraging self-actualization, supporting avenues for self-help, providing opportunities for gainful employment, and fostering a sense of belonging and self-esteem [9]. Help in adapting to a new cultural environment and lifestyle, such as learning the local language, norms, and customs, is vital to successful assimilation and integration of migrants and minorities in a way that preserves their dignity, independence, and selfrespect as well as commitment to absorption and inclusion in their host country.

\section{Discussion and recommendations}

Facilitated by the three working groups, the Workshop participants prepared a summary and draft recommendations related to the political, social, and public health aspects of the migrant crisis. Problem areas identified in migrant and minority health, along with examples and possible interventions, are listed in Table 1.

Public health and its representatives have a duty to ensure the ethical guardianship of global health standards for all vulnerable groups-including migrants-through the use of their many professional competencies across sectors. Public health refers to all organized measures (whether public or private) to prevent disease, promote health, and prolong life among the population as a whole [10]. The WHO states that health is a state of complete physical, mental, and social well-being-not merely the absence of disease or infirmity 
Table 1 Problem areas and possible interventions to improve migrant and minority health

\begin{tabular}{ll}
\hline Problem area & Specific problem \\
\hline $\begin{array}{l}\text { Knowledge } \\
\text { gap in migrant } \\
\text { health }\end{array}$ & $\begin{array}{l}\text { Policymakers, supervisory staff, and direct } \\
\text { givers lack training on migrant health issues. } \\
\text { Community health workers are not } \\
\text { adequately prepared to address the unique } \\
\text { needs of refugees and their families. }\end{array}$ \\
$\begin{array}{l}\text { Basic needs } \\
\text { provision }\end{array}$ & $\begin{array}{l}\text { Inadequate and/or deteriorating shelter, } \\
\text { sanitation, waste disposal, and clean water } \\
\text { facilities }\end{array}$
\end{tabular}

Nutritional security

Infectious disease control provision

Access to medical care

Noncommunicable disease

Maternal and child health

Education and free time
Managing changes in risk for nutritional disorders (including problems with breastfeeding), exposure to violence and trafficking, and other factors affecting women's sexual and reproductive health

Increased demand on schooling and education systems for boys and girls
Example policy intervention

Provide training to public health leaders, including policymakers, supervisory staff, direct care workers, and community health workers

Consult migrants and refugees themselves about how best to sustain and promote migrant health

Increase monitoring of water supply and sanitary facilities

Increase repair and supply of facilities as needed and feed this information back into plans for preparedness and response

Ensure provision of vitamin- and mineralfortified foods Distribute vitamin and mineral supplements, particularly for the most vulnerable migrants including children, pregnant women, and the elderly

Promote screening, vaccination, and treatment among migrant populations Facilitate better health record keeping for migrants

Harmonize vaccination policy across the European Region

Access to use of mental health service Education, self-help group activities, surveys, and specific interventions

Improve migrant access to the health system Curative and preventive medicine interventions

Promote increased education and preventive screenings

Improve health monitoring of noncommunicable diseases among migrants, particularly through improved health record keeping (both e-records and hand carried printed records)

Promote micronutrient-fortified (e.g., vitamins A, B, C, D, iodine, iron, folic acid) food staples (e.g., flour, milk, salt)

Enhance protection against female genital mutilation, sexual exploitation, and child marriages at all stages of the migrant journey Promote migrant and refugee education programs focused on adapting to norms and standards of host countries

Availability and access for pre-kindergarten programs, open public spaces for children's play, family literacy programs

Ensure developmental and intellectual stimulation for children at all stages of development along the migrant journey Improve child development and health monitoring for migrants

Semi-structured active free time for play, visiting host-heritage sites (museums, galleries, concerts), organizing local tours, holidays, etc.

Improve health monitoring of migrants with disabilities through improved record keeping Promote access to health, education, and employment services for those with disabilities 
Table 1 Problem areas and possible interventions to improve migrant and minority health (Continued)

\begin{tabular}{lll}
\hline LGBT health & Increased vulnerability to depression, & Eliminate discrimination and promote equal \\
substance abuse, and acquiring HIV and other & access to health services regardless of sexual \\
sexually transmitted infections & orientation \\
& $\begin{array}{l}\text { Provide education of risks and preventative } \\
\text { interventions, both along the migrant journey } \\
\text { and within the host country }\end{array}$
\end{tabular}

[11]. Furthermore, health is a human right, based on the principles of justice, equity, and social solidarity. By transcending state boundaries to respond to public health challenges (such as the current migrant crisis in Europe), public health professionals and organizations can promote health for all and advancing well-being on a global scale.

History will judge how this crisis is addressed. The European community must draw from its collective memory of the massive displaced person experience following World War II and the Holocaust and from more recent recollections of the Balkan wars of the 1990s. Europe should be generous in giving humanitarian help for those who respect commonly accepted "European values" based on the principle of solidarity.

Sovereign states have concurrent concerns regarding the massive inflow of refugees, which may include security threats. In response, countries may introduce screening practices and may prefer legitimately documented refugees and survivors of genocidal action in their home countries to other migrants. Many countries will limit total migration to a number that can be managed and absorbed into the society while adhering to international law. We must work collectively (i) to avoid inconsistent practices and the introduction of new border restrictions and (ii) to ensure that international laws, ethical standards, and the rights of migrants and minorities are respected.

Solving the complex problems of migrant and minority health requires us to think through the interests and motivations of a number of actors, including governments, humanitarian agencies and their workers, academics, and the media. The organizational, financial, and human resource allocation needed to meet the health challenges of the current crisis will require high-level coordination at political, professional, and technical levels. Governments must work together with international governmental and nongovernmental organizations to achieve consensus and share responsibilities and best practices on how to address migrant and minority health issues.

Addressing the health aspects of the migrant crisis is important because protecting and promoting migrant health is inextricably linked to public health. National governments have already demonstrated an ability to reach agreement on a number of areas concerning the current migrant crisis in Europe. The steps outlined in Table 1 for protection, basic needs, and health promoting activities are critical for addressing the health aspects of the migrant crisis facing Europe today.

\section{Endnotes}

${ }^{1}$ Prof. Wolfgang Aulitzky (American Austrian Foundation), Laurent Chambaud (PHR), and Robert Otok (ASPHER) brought greetings from their respective organizations. Prof Ted Tulchinsky was the Workshop Coordinator, Mariam Torosyan was the Rapporteur, and Lukasz Balwicki was the Working Group Coordinator. Tina Bregant prepared a summary of the Workshop, and Amanda Shriwise assisted in preparing and editing the report. 


\section{Appendix 1}

Table 2 Salzburg Workshop on migrant and minority health, 3-9 April 2016 participants, rapporteurs, and working groups

\begin{tabular}{|c|c|c|}
\hline Name & Affiliation/country & Contact \\
\hline \multicolumn{3}{|l|}{ Organization } \\
\hline 1. Wolfgang Aulitzky & American Austrian Foundation & w.aulitzky@openmedicalinstitute.org \\
\hline 2. Laurent Chambaud & $\begin{array}{l}\text { ASPHER/PHR Editor-in-chief/ } \\
\text { EHESP }\end{array}$ & laurent.chambaud@ehesp.fr \\
\hline 3. Jonathan Cohen & Open Society Foundations-NY & jonathan.cohen@opensocietyfoundations.org \\
\hline 4. Robert Otok & ASPHER & robert.otok@aspher.org \\
\hline 5. Sarabeth Harrelson & Open Society Foundations-NY & sarabeth.harrelson@opensocietyfoundations.org \\
\hline \multicolumn{3}{|l|}{ Guest lecturers } \\
\hline 1. Isabel de la Mata & $\begin{array}{l}\text { Principal Advisor } \\
\text { Health and Crisis Management } \\
\text { DG SANTE, European Commission }\end{array}$ & Isabel.delamata@ec.europa.eu \\
\hline 2. Santino Severoni & $\begin{array}{l}\text { Coordinator } \\
\text { Public Health and Migration } \\
\text { WHO EURO }\end{array}$ & sev@euro.who.int \\
\hline 3. Thomas Nierle & $\begin{array}{l}\text { President } \\
\text { MSF, Switzerland }\end{array}$ & thomas.nierle@geneva.msf.org \\
\hline 4. Gustavo Fernandez & MSF, Switzerland & Gustavo.fernandez@geneva.msf.org \\
\hline \multicolumn{3}{|l|}{ Faculty } \\
\hline 1. Dawn Davis & USA & ddavis32@slu.edu \\
\hline 2. Seth M. Holmes & USA/Germany & sethmholmes@berkeley.edu \\
\hline 3. Mark Johnson & UK & mrdj@dmu.ac.uk \\
\hline 4. Slava Plavinski & Russia & splavinskij@mail.ru \\
\hline 5. Bernd Rechel & UK & Bernd.Rechel@lshtm.ac.uk \\
\hline 6. Fredrik Saboonchi & Sweden & fredrik.saboonchi@rkh.se \\
\hline 7. Ted Tulchinsky & Israel & tulchinskyted@hotmail.com \\
\hline 8. Anita Villerusa & Latvia & Anita.Villerusa@rsu.Iv \\
\hline \multicolumn{3}{|l|}{ Fellows } \\
\hline 1. Kristina Astromske & Lithuania & astromske@gmail.com \\
\hline 2. Fabienne Azzedine & France & fabienne.azzedine@ehesp.fr \\
\hline 3. Lukasz Balwicki & Poland & balwicki@gumed.edu.pl \\
\hline 4. Levan Baramidze & Georgia & levan23@hotmail.com \\
\hline 5. Manana Beruchashvili & Georgia & mberuchashvili@yahoo.com \\
\hline 6. Tina Bregant & Slovenia & tina.bregant.drmed@gmail.com \\
\hline 7. Heide Castañeda & USA/Germany & hcastaneda@usf.edu \\
\hline 8. Nina Chala & Ukraine & ninachala@yandex.ua; chala_nina@ukr.net \\
\hline 9. Daniel Chemtob & Israel & daniel.chemtob@moh.health.gov.ll \\
\hline 10. Alma Cicic & Montenegro & Alma.cicic@ijzcg.me \\
\hline 11. Catherine Cook & Canada & Catherine.Cook@umanitoba.ca \\
\hline 12. Jo Durham & Australia & m.durham@uq.edu.au \\
\hline 13. Ivan Froes & Ukraine & ifroes@iom.int, ipfroes@yahoo.com.br \\
\hline 14. Ana Hijaz & Spain & aihijas@fhalcorcon.es \\
\hline 15. Mariela Kamburova & Bulgaria & mariela_kamburova@yahoo.com \\
\hline 16. Gjuro Krenkovski & Macedonia & AAF/OMl fellow \\
\hline
\end{tabular}


Table 2 Salzburg Workshop on migrant and minority health, 3-9 April 2016 participants, rapporteurs, and working groups (Continued)

\begin{tabular}{|c|c|c|}
\hline 17. George Koulierakis & Greece & gkoulierakis@esdy.edu.gr \\
\hline 18. Peter Krcho & Slovakia & peter.krcho@upjs.sk \\
\hline 19. Anna Kryukova & Russia & russia.omi@gmail.com \\
\hline 20. Raj Kumar Rai & India & rajesh.iips28@gmail.com \\
\hline 21. Vladimir Lazarevik & Macedonia & vlazarevik@healthgrouper.com \\
\hline 22. Oleg Lozan & Moldova & oleg.lozan@usmf.md \\
\hline 23. Bojana Matejic & Serbia & bmatejic@med.bg.ac.rs \\
\hline $\begin{array}{l}\text { 24. Milena Santric- } \\
\text { Milicevic }\end{array}$ & Serbia & msantric@med.bg.ac.rs \\
\hline 25. Lisa Ploeg & The Netherlands & I.ploeg@student.maastrichtuniversity.nl \\
\hline 26. Pawel Pludowski & Poland & p.pludowski@czd.pl \\
\hline 27. Lisa Rubin & Israel & lisa.rubin@MOH.GOV.IL \\
\hline 28. Amanda Shriwise & UKUSA & amanda.shriwise@spi.ox.ac.uk \\
\hline 29. Mariam Torosyan & Armenia & torosyan.mariam9@gmail.com \\
\hline 30. Dima Tsanova & Bulgaria & d_krumova@abv.bg \\
\hline 31. Christian Wejse & Denmark & wejse@dadlnet.dk \\
\hline 32. Elisabetta de Vito & Italy & devito@unicas.it \\
\hline 33. Hande Bahadir & Turkey & Handebahadir86@gmail.com \\
\hline 34. Stuart McClean & UK & Stuart.macclean@uwe.ac.uk \\
\hline 35. Marius Pop & Romania & mpop@iom.int \\
\hline
\end{tabular}

\section{Abbreviations}

ASPHER: Association of Schools of Public Health in the European Region; IOM: International Organization for Migration; MSF: Médecins Sans Frontières; PHR: Public Health Reviews; WHO: World Health Organization

\section{Acknowledgements}

Our thanks go to the American Austrian Foundation and its Director, Professor Wolfgang Aulitzky, for his warm hospitality and support, along with his outstanding staff including Ms. Elisabeth Bourg and others of the provision of hospitality, facilities, and superb organization. We thank Mr. Jonathan Cohen of the Open Society Foundation of New York for participating in the Workshop. Special thanks go to Mr. Robert Otok, Manager of the Association of Schools of Public Health in the European Region (ASPHER) for his outstanding contribution to the organization of the Workshop. Finally, we wish to acknowledge and thank the migrant and minority health workshop participants, listed in Appendix 1, whose presentations on specific aspects of the migrant health crisis informed this piece and especially the Working Group leaders-Catherine Cook, Stuart McClean, Jo Durham, Lisa Ploeg, and Prof. Elisabetta de Vito.

This report is sponsored by the American Austrian Foundation in cooperation with the Association of Schools of Public Health in the European Region and Public Health Reviews 30 August 2016.

\section{Funding}

American Austrian Foundation conducted the Workshop providing accommodation, travel costs, facilities, staff, and support services

\section{Availability of data and materials}

Provided by presenters.

\section{Authors' contributions}

MT drafted the editorial; TB contributed a summary of the conference proceedings that served as a foundation for the editorial and contributed toward revising several drafts; AS edited the structure and content of the editorial; LB oversaw the submission of working group reports that informed the editorial and offered comments on a number of drafts; TT as moderator of the Workshop oversaw this process and contributed to editing and final revisions of the editorial. All authors read and approved the final manuscript.

\section{Competing interests}

The authors declare that they have no competing interests.

\section{Consent for publication}

Not applicable. 
Ethics approval and consent to participate

Not applicable.

\section{Author details}

${ }^{1}$ University Rehabilitation Institute, Republic of Slovenia, Ljubljana, Slovenia. ${ }^{2}$ Faculty of Public Health, Yerevan State Medical University, Yerevan, Armenia. Institute of Philosophy, Sociology and Law, National Academy of Sciences of the Republic of Armenia, Yerevan, Armenia. ${ }^{4}$ Department of Sociology, Harvard University, Cambridge, MA, USA. ${ }^{5}$ Department of Social Policy and Intervention, University of Oxford, Oxford, UK. ${ }^{6}$ Department of Public Health and Social Medicine, Medical University of Gdansk, Gdansk, Poland. 'Braun School of Public Health and Community Medicine, Hebrew University Hadassah, Jerusalem, Israel. ${ }^{8}$ School of Health Sciences, Ashkelon Academic College, Ashkelon, Israel.

Received: 27 September 2016 Accepted: 16 November 2016

Published online: 28 November 2016

\section{References}

1. United Nations News Centre. Available at: http://www.un.org/apps/news/story.asp?NewsID=53341\#.VwuZTPI97|U. (Accessed 11 Apr 2016).

2. Centres for Disease Control and Prevention. Immigrant and refugee health: refugee health quidelines, 12 November 2013. Available at: http://www.cdc.gov/immigrantrefugeehealth/guidelines/refugee-guidelines.html. (Accessed 11 Apr 2016).

3. UNHCR UN Refugee Agency. Available at: http://www.unhcr.org/564da0e3b.html. (Accessed 11 Apr 2016).

4. UNHCR and the International Organization for Migration. Regional refugee and migrant response plan for Europe: Eastern Mediterranean and Western Balkans route. Available at: http://rmrp-europe.unhcr.org/2016_RMRP_Europe. pdf. (Accessed 7 May 2016)

5. International Organization for Migration. Mixed migration flows in the Mediterranean and beyond: compilation of available data and information, 21 April-3 May 2016. Available at: https://issuu.com/iomdrd/docs/weekly_flows_ compilation_no14_4_ma. (Accessed 7 May 2016).

6. United Nations 1948 Universal Declaration of Human Rights. Available at: http:/www.un.org/en/universaldeclaration-human-rights/. (Accessed 7 May 2016).

7. United Nations 1948 Convention on Prevention and Punishment for the Crime of Genocide. Available at: https:// treaties.un.org/doc/publication/unts/volume\%2078/volume-78-i-1021-english.pdf. (Accessed 7 May 2016).

8. United Nations Convention and Protocol Relating to the Status of Refugees. Text of the 1951 Convention relating to the status of refugees, Text of the 1967 Protocol relating to the status of refugees, and Resolution 2198 (XXI). Available at: http://www.unhcr.org/3b66c2aa10.html. (Accessed 7 May 2016).

9. Maslow AH. A theory of human motivation. Psychol Rev. 1943;50(4):370-96. Available at: https://docs.google.com/ file/d/OB-5-JeCa2Z7hNiZINDNhOTEtMWNkYioOYmFhLWI3YjUtMDEyMDJkZDExNWRm/edit. (Accessed 5 May 2016).

10. World Health Organization. Glossary of globalization, trade and health terms. Public health. Available at: http:// www.who.int/healthpromotion/about/HPR\%20Glossary\%201998.pdf. (Accessed 11 Apr 2016).

11. World Health Organization. WHO Health Definition. Available at: http://www.who.int/about/definition/en/print. html (Accessed 11 Apr 2016).

\section{Submit your next manuscript to BioMed Central and we will help you at every step:}

- We accept pre-submission inquiries

- Our selector tool helps you to find the most relevant journal

- We provide round the clock customer support

- Convenient online submission

- Thorough peer review

- Inclusion in PubMed and all major indexing services

- Maximum visibility for your research

Submit your manuscript at www.biomedcentral.com/submit 